be of great importance for the prognosis of the tumour and in part may serve as guidelines for the mode of therapy to be chosen. Several other recent studies confirm this suggestion..$^{2-5}$ Radical excision of the tumour and postoperative radiotherapy seem to be the choice of treatment when the degree of malignancy of the tumour is low (grade I). When the tumour is classified as highly malignant (grade II or III), the probability of later metastasis seems so great that therapy with a combination of cytostatic agents should be applied after surgery and radiotherapy. ${ }^{6}$ The advantages of limb amputation seems to be limited to only a few selected cases.

Until recently angiography has been little used in the diagnosis of soft-tissue sarcomas, since the evidence on the diagnostic advantages of this method has been to some extent contradictory. During the past decade the use of vasoactive agents has much improved the reliability of this method. ${ }^{7} 8 \mathrm{~A}$ recent angiographic study on 35 soft-tissue sarcoma patients in the University Central Hospital, Helsinki, Finland, suggests that a preoperative angiography is very useful in defining the size and vascular supply of the tumour. ${ }^{9}$ Further, this study reports on the usefulness of pharmacoangiography in defining the character as well as the size of the tumour. Tumour recurrences seemed, however, to present a radiological diagnostic problem.

SePpo SANTAVIRTA

SAARA TÖTTERMAN

PeNTTI GRÖHN

ERKKI HEINONEN

JERKER SANDELIN

BÖRJE SUNDELL

University Central Hospital,

Helsinki, Finland

${ }^{1}$ Santavirta, S, et al, Proceedings of the Finnish Orthopaedic Association, 1978, 1, 110 inedo, H M, Cancer Treatment Reviews, 1977 , 4, 67

Suit, H D, and Russell, W O, Cancer, 1977, 39, 830 erf-Messing, B, and Unnik, J A M, Cancer, 1965, $18,1113$.

Russell, W, et al, Cancer, 1977, 40, 1562

Ekelund, L, and Lunderquist, A, Radiology, 1974, 110, 533 .

Hawkins, I, and Hudson, T, Radiology, 1974, 110, 541

Totterman, S, and Santavirta, S, Proceedings of the Finnish Orthopaedic Association, 1978, 1, 113 .

\section{The grumbling appendix}

SIR,-While a scar in the right iliac fossa may be a comfort to Mr J W Maltby (1 September, p 555) when faced with an acute abdomen, it may also be a trap for the unwary. Firstly, the appendix may not have been removed if an alternative procedure was performed through an "appendix incision." Secondly, failure to remove all of the appendix leaves an appendiceal stump which may subsequently be the site of inflammation and even perforation, as the following case illustrates.

A 44-year-old woman from Japan presented with a 10-day history of increasingly severe right iliac fossa pain associated with vomiting and later with diarrhoea. She gave a firm history of appendicectomy for "severe appendicitis" performed in Japan 10 years previously. On the second and seventh days of her illness she consulted two separate general practitioners, both of whom diagnosed gastroenteritis. Examination revealed an ill, dehydrated lady with signs of peritonitis; there was a "gridiron" scar in the right iliac fossa. At laparotomy, performed after resuscitation, there was purulent free fluid and a large abscess cavity was found in the right iliac fossa between the caecum and adjacent loops of small bowel; at the base of the abscess cavity was an acutely inflamed, perforated, appendiceal stump $1 \mathrm{~cm}$ in length. A further appendicectomy was performed together with peritoneal toilet. The patient made an uneventful recovery.

Although the management of the appendix stump has received much attention little emphasis has been placed on the need to excise the whole appendix. "Subtotal" appendicectomy results from failure to appreciate the full length of the appendix, because either it is kinked and bound to the caecum by adhesions or oedema of the adjacent caecum obscures the appendix base.

In the reported case it is likely that the history of appendicitis and the presence of the appropriate scar resulted in delay of diagnosis and treatment of what is still a lethal disease.

Professorial Surgical Unit,

David Francis

Royal Victoria Infirmary,

Newcastle upon Tyne NE1 4LP

\section{Susceptibility to primary biliary cirrhosis}

SIR,-We have read with great interest the article by Drs J G Douglas and N D C Finlayson concerning individual susceptibility and environmental factors for the development of primary biliary cirrhosis (18 August, $p$ 419). In the two reported families, the authors did not find any association between HLA antigens and the disease, but they did not look for the HLA-DR antigens.

Recently we have studied 21 patients with primary biliary cirrhosis and we found an increase in DRW $3(57 \cdot 1 \%)$ in relation to the control group $(14.8 \%)(P<0.004)$. Details of this investigation are to be published in Tissue Antigens.

Since the antigen DRW 3 is mostly associated with autoimmune disorders, and it seems also to be related with primary biliary cirrhosis, the hypothesis of a genetic basis is strengthened. The presence of DRW 3 is not an absolute requirement, and some still unknown environmental factors may act as a triggers for the development of the disease, as suggested by Douglas and Finlayson.

F Arriaga Chapper A Pares Arnaculleta G ERcilla Gonzalez M Bruguera CoRTada

Department of Immunology and J RODES Liver Unit, Barcelona, Spain

\section{Serum bilirubin and hepatic enzyme} induction

SIR,-I was interested to read the paper by Dr A K Scott and his colleagues (4 August, p 310). Their results confirm our report of low total bilirubin levels in epileptic patients receiving treatment. ${ }^{1}$ I am less happy, however, than they are about the simplicity of measuring bilirubin levels in blood. Even with modifications to the basic Malloy and Evelyn method, such as that described by Michaelsson et al," it is doubtful whether low total bilirubin concentrations can be reliably measured; this is especially so when one uses diazo methods to measure concentrations in the normal range. Not only the timing of venesection but also the marked effects of feeding are well known. I would therefore caution against hoping that bilirubin levels can be used as an indicator of hepatic enzyme induction, attractive as it also seemed to us a few years ago.

I also wonder how a liver biopsy can be used to "assess hepatic enzyme induction."

\section{R P H THOMPSON}

St Thomas's Hospital,

1 Thompson, R P H, et al, Lancet, 1, 21.
' Michaelsson, M, et al, Pediatrics, 1965, 35, 925

\section{Spontaneous recovery from rapidly progressive glomerulonephritis}

SIR,-The title chosen by Dr Douglas $R$

Maxwell and others (15 September, p 643) appears somewhat unfortunate, since the "spontaneous" recovery followed prolonged dialysis. Moreover, the cases described had about $50 \%$ glomerular crescents, and although the term "rapidly progressive glomerulonephritis" is sometimes applied when the proportion of crescents is even smaller ${ }^{1}$ to define a prognostic group it should probably be confined to patients with $70 \%$ or more crescents." Even in such cases, and in the presence of oliguria, we have found the occasional patient who recovers useful renal function.

A less misleading title might have been "Residual renal function in extracapillary glomerulonephritis treated by dialysis alone."

David J Evans

Department of Histopathology

Royal Postgraduate Medical School,

Hammersmith Hospital,

${ }^{1}$ Olsen, S, Acta Pathologica et Microbiologica Scandanavica [A], 1974, 82, suppl, p 249.

Cameron, J S, and Ogg, C S, in Glomerulonephritis: Morphology, Natural History and Treatment, ed
$\mathrm{P}$ Kincaid-Smith, T H Mathew, and E L Becker, part II, p 735. Yew York, John Wiley and Sons, part II, p 735. Yew York, John Wiley and Sons,
1973. Richards, P, Evans, D J, and
Medical fournal, 1968, 2, 259.

\section{Kidney transplants and long-term immunosuppression}

SIR,- The paper by Dr F Di Padova and others (18 August, $p$ 421) questions the necessity of long-term immunosuppressive therapy after kidney transplantation. We would like to report on a patient whose selfinitiated withdrawal of azathioprine and steroid medication did not have such a favourable outcome for the function of his transplant.

The patient, a 20-ycar-old man, was first seen in August 1972, when chronic glomerulonephritis was diagnosed. In December 1972 chronic hemodialysis therapy was instituted because of end-stage renal failure, and in March 1973 he received a kidney transplant from a cadaveric donor. HLA-typing revealed poor histocompatibility, with one mismatch at the $A$ and two mismatches at the B locus. Immediately after the transplantation a good graft function was obtained, and except for one acute rejection episode in the early post-transplant period no further complications were observed. Immunosuppressive therapy consisted of azathioprine and prednisolone as usual. Under a regimen of $100 \mathrm{mg}$ azathioprine and $7.5 \mathrm{mg}$ prednisolone a day the patient had an excellent transplant function for five years, his plasma creatinine concentration being consistently about $133 \mu \mathrm{mol} / 1$ $(1.5 \mathrm{mg} / 100 \mathrm{ml})$. 
In February 1978 the patient went skiing with his school colleagues, and being afraid of taking drugs in the presence of his friends he stopped taking his immunosuppressive therapy for two weeks. Seen again at the end of March $1978 \mathrm{~h}$ was azotaemic, with a plasma creatinine of 884 $\mu \mathrm{mol} / 1(10.0 \mathrm{mg} / 100 \mathrm{ml})$. An open biopsy of the transplant showed the signs of an acute interstitial graft rejection. Under high-dose steroids administered in addition to his continuous immunosuppressive regimen the graft function improved again, and since June 1978 the plasma creatinin is stable at about $256 \mu \mathrm{mol} / 1(2.9 \mathrm{mg} / 100 \mathrm{ml})$.

The history of our patient, showing an acute graft rejection episode five years after kidney transplantation, demonstrates clearly the danger of discontinuing immunosuppressive therapy in renal allograft recipients. We therefore would like to suggest that withdrawal of immunosuppressive therapy should be limited to cases of hazardous and lifethreatening side effects of these drugs in this group of patients.

H GRAF

H K STUMMVOL W F PINGgerA

Second Department of Medicine, University of Vienna,

Vienna, Austria

\section{On-demand analgesia equipment}

SIR,-Mr T Lind and his colleagues (1 September, $p$ 548) in their letter about our paper (21 July, p 166) raise three important points in the assessment of apparatus which can be used by the patient to deliver analgesic drugs on demand.

Firstly, there is always the problem of the "phantom knob twiddler." Mr Lind's solution of covering the thumbwheel control of the Cardiff Palliator seems excellent; with the Janssen prototype, once the machine is started on its run turning the switches has no effect. Essentially they provide settings for the microprocessor and once the machine is "initiated" changing the settings does not alter the microprocessor settings.

Secondly, Mr Lind and his colleagues ask if the Janssen machine can be programmed to set a maximum total dose as well as a maximum dose each hour. The answer is no, except that such a maximum dose could be added initially to the infusion bag. The third point they raise is whether the performance of the printer is satisfactory, so that operators can determine easily when the drug was las given. In our hands the recorder has not let us down.

We did not mention the cost of the machine. This version is a prototype. Shortly we hope to look at the performance of a production model.

W D White

D J PEARCE

J NORMAN

University Department of Anaesthetics,

Southampton General Hospital,

Southampton SO9 4XY

\section{Unusual haemolytic-uraemic syndrome}

SIR,-In my opinion the case of haemolytic uraemia that was discussed at the clinicopathological conference (21 July, p 179) was unusual because it was very likely to have been exacerbated by the high-dose intravenous pyelogram that was performed after the onset of the illness. We are not given details of the patient's urinary output. It is now well known that $x$-ray contrast medium will precipitate anuria in oliguric patients. ${ }^{1}$ In part this is because it can cause some intravascular coagulation within the renal circulation. If this is the true explanation it would provide a salutary lesson. Moreover, such a sequence will explain why the patient had neither bruising nor an elevated bilirubin and why the anaemia and the red cell fragmentation only appeared some days later.

In retrospect we do not know whether the patient's renal endarteritis was caused by malignant hypertension alone or whether she actually had a Shwartzman reaction caused by a urinary tract infection. The white cells in the urine would favour the latter even though bacterial culture after admission was negative. Since gastroenteritis or urinary tract infection is a common accompaniment of the haemolyticuraemic syndrome, which many believe to be a Shwartzman equivalent, ${ }^{2}$ the correct way to make a retrospective diagnosis is to monitor such a patient's antilipid-A antitoxin antibody levels. ${ }^{3}$ When there has been a previous Gram-negative infection causing the haemolytic-uraemic syndrome the antibody titres will rise.

E N WARDLE

King's College Hospital

'Alexander, R D, Berkes, S L, and Abuelo, J G, Archives of Internal Medicine, 1978, 138, 381.

3 Wardle, E N, British fournal of Hospital Medicine, 1979, 22, 104 .

\section{Marital pathology and the choice of partner}

SIR,-I am enjoying Dr J Dominian's series of articles on marital pathology.

According to Toman, ${ }^{1}$ there is another important factor in the choice of partnernamely, position in the sibship. Thus, if the elder brother of a younger sister marries the younger sister of an older brother, a stable marriage is probable. In this case the man is used to leading and looking after a younger girl while the girl is used to being led and to understanding an older man. An example of a marriage likely to fail is between the oldest brother of brothers and the oldest sister of sisters-in this case there will be rank conflict and gender conflict.

There are, of course, many other combinations, which have various probable outcomes. 'Toman gives statistical evidence that these factors are important.

Peter ToMson

Abbots Langley, Herts WD5 0AL

1 Toman, W, Family Constellations: Effects on Personality and Social Behaviour. New York, Springer Publishing Company, 1976.

\section{Mechanical aids to ventilation for use} in the field

SIR,-Dr M G Harries is to be complimented on a most useful review of emergency resuscitation equipment (18 August, p 426). However, his recommendations regarding ventilatory resuscitators are questionable. A recent evaluation ${ }^{1}$ of seven gas-powered resuscitators including the Marion Flynn series 3, found that all the devices failed according to at least one criterion of safety. Common problems were excessive airway pressure and falling inspiratory flow rates when used with a test lung.
It is apparent that resuscitators giving gas flow rates of over 100 litres a minute will generate high pressures at the airway in patients with normal lung mechanics. In the face of abnormal respiratory mechanics this will lead to leakage of gas at the pressure relief valve if fitted.

While I agree that pressure-cycled mechanical resuscitators are unsatisfactory, automatic time-cycled devices may have advantages in allowing cardiac massage to synchronise with artificial ventilation and in facilitating the transport of the patient.

R GREENBAUM

Department of Anaesthetics,

Brenchay Hospital,

${ }^{1}$ Health Devices, 1978, 18 (2), 24.

\section{Diagnostic imaging}

SIR,-Your leading article (22 September, p 690) on diagnostic imaging is indeed appropriate. However, the problems of obtaining and replacing radiological equipment must also be considered as this can have a significant effect on consultants' morale. The lack of modern equipment makes some departments unable to perform even renal angiography.

Radiological (and laboratory) equipment is expensive but, in my experience, health boards do not normally make any provision for the replacement of old equipment, merely relying on hope to come up with the cash when machines finally break down, with consequent reduction in services for several months while new equipment is being found-and all this despite numerous warnings and requests from radiologists with advice from appropriate scientific committees.

ROBERT H CORBETT

Hairmyres Hospital,

Glasgow G75 8RG

\section{Cubital tunnel syndrome}

SIR,-I read with interest Dr $T$ G Wadsworth's letter on the cubital tunnel syndrome (22 September, p 736). Perhaps I may be allowed to report my unpublished observations.

A 14-year-old boy presented with a complete bilateral ulnar palsy. He said that he first discovered the condition of his hands at the end of a three-hour hill walk during which he had kept his thumbs tucked under the shoulder straps of his rucksack. My curiosity being aroused, I asked about antecedent forearm flexion in all subsequent cases. During the following year I diagnosed the condition in 16 patients and in all but one I judged prolonged forearm flexion to be the cause. The exceptional patient was later shown to have a ganglion. In 10 patients the forearm flexion had occurred during sleep and in five while awake.

Gowers $^{1}$ disagreed with the view of Duchenne that external pressure is a cause of ulnar palsy and stated, "It is much more common for the nerve to suffer in longcontinued flexion of the elbow, without external pressure, and from this cause the nerve is sometimes paralysed during sleep. I have three times seen a sleep palsy of the ulnar nerve." An experiment suggested itself. I asked several students to roll up their 